(2) Open Access Full Text Article

ORIGINAL RESEARCH

\title{
Impact of cough and mucus on COPD patients: primary insights from an exploratory study with an Online Patient Community
}

This article was published in the following Dove Press journal:

International Journal of Chronic Obstructive Pulmonary Disease

\author{
Nigel Cook' \\ Jennifer Gey' \\ Beyza Oezel' \\ Alexander J Mackay ${ }^{2}$ \\ Chitresh Kumari ${ }^{3}$ \\ Vinay Preet Kaur ${ }^{3}$ \\ Noel Larkin ${ }^{4}$ \\ Jennifer Harte ${ }^{4}$ \\ Sara Vergara-Muro 5 \\ Florian S Gutzwiller' \\ 'Novartis Pharma AG, Basel, Switzerland; \\ ${ }^{2}$ Airways Disease Section, Imperial \\ College London, London, UK; ${ }^{3}$ Novartis \\ Healthcare Private Ltd, Hyderabad, India; \\ ${ }^{4}$ Novartis Global Service Center, Dublin, \\ Ireland; ${ }^{5}$ Ipsos Healthcare, London, UK
}

Correspondence: Nigel Cook

Novartis Pharma AG, WSJ-210.14.30.14,

Basel $\mathrm{CH}$ 4056, Switzerland

$\mathrm{Tel}+4$ I6I 3245273

Email nigel.cook@novartis.com
Background: Qualitative research provides real-life information on patients' condition and facilitates informed design of future clinical studies.

Objective: We used Online Communities as a qualitative research tool to evaluate the effect of cough and mucus on COPD patients.

Methods: Two 2-week Online Communities were run in parallel in the UK and in the USA, including COPD patients with persistent cough and excessive mucus. Patients anonymously posted their responses to pre-assigned tasks, supervised and guided by a trained moderator. Five themes around the impact of cough and mucus were explored with new questions posted every 2-3 days. On the final day, high-level conclusions were shared with patients for feedback. Data were analyzed following the principles of grounded theory.

Results: Twenty COPD patients (UK, $n=10$; USA, $n=10$ ) participated in the Online Communities. We found that cough and mucus disrupted COPD patients' lives at functional, emotional, social and economic levels. Patients created daily rituals and adjusted their lifestyle to cope with the impact of these symptoms. Patients identified themselves with our conclusions and saw the Online Community as an effective forum to share their experiences.

Conclusion: Findings of our study add to the body of evidence on the negative impact of COPD symptoms and unmet needs of these patients.

Keywords: chronic obstructive pulmonary disease, cough, mucus, Online Community, online bulletin board, qualitative research

\section{Introduction}

COPD is a highly prevalent inflammatory disease of the lungs, caused by long-term exposure to noxious particles or gases and marked by persistent airflow limitation and respiratory symptoms. ${ }^{1}$ COPD claimed 3 million lives in 2016 , making it the third leading cause of death worldwide. $^{2}$ In addition to significantly affecting patients' quality of life (QoL), COPD is associated with increased morbidity and mortality and contributes to a substantial socioeconomic burden on patients and society. ${ }^{3}$ On top of breathlessness and exacerbations (acute worsening of respiratory symptoms), COPD patients frequently experience recurrent cough and excessive mucus production. ${ }^{4,5}$ A recent study, a social media listening with COPD patients, revealed their concern about cough and excessive mucus/phlegm production. ${ }^{6}$ Moreover, persistent cough and excessive mucus production may negatively impact on many aspects of patient's daily lives, regardless of disease stage. ${ }^{6,7}$ 
Qualitative health care research tools are used to gather real-life information about the impact of a disease or condition on patients' lives, offering critical insights which can influence the design of future therapies and clinical trials. ${ }^{8,9}$ Traditional qualitative research typically involves telephonic or face-to-face interviews or focus groups. However, these techniques can miss patients' more sensitive and emotional issues that they feel uncomfortable talking about publicly. ${ }^{10} \mathrm{~A}$ greater understanding of the emotional impact, perceptions and preferences of patients may be important in COPD, a condition where patients are often burdened by shame and guilt and have psychosocial challenges. ${ }^{6,11,12}$ In this regard, online qualitative research approaches offer advantages over the traditional techniques in terms of anonymity and convenience (possibility to participate from their time and place of choice), whilst bringing together people with the same condition from diverse geographical locations. ${ }^{13}$ Apart from the advantages outlined above, because an Online Community (sometimes referred to as online bulletin board) continues over a period of days or weeks, participants can build comfort and rapport in sharing experiences with one another. ${ }^{13}$ The anonymity and social community atmosphere created amongst people suffering and sharing "like" experiences, stimulate an open and rich online discussion (captured verbatim in their own words and phrases), even on more emotional and sensitive research themes. ${ }^{13}$ From the moderator/researcher perspective, this also allows an opportunity to pose follow-up questions to clarify, go deeper in certain areas or explore if others in the group had shared experiences; there is additionally the option to have one-to-one online conversations with a single individual in a private setting. ${ }^{14,15}$

In this study, we utilized an Online Patient Community to assess the impact of cough and excessive mucus secretion on different aspects (including functional and emotional) of the lives of patients with COPD.

\section{Methods}

\section{Study objectives}

The aim of this study was to understand the impact of cough and mucus on the QoL of COPD patients. We explored the ways in which patients, in their own words, perceived their experiences and symptoms, in particular cough and mucus, and consequences thereof. Additionally, the study aimed to identify current strategies that people living with the condition use to cope with the impact of cough and mucus. Finally, the study attempted to gain insight into the current unmet needs in treatments regarding COPD symptom management, including emotional and psychosocial needs of the patients.

\section{Study design}

This was a qualitative study, reported in line with the Guidance for Reporting Involvement of Patients and the Public 2 (GRIPP2) checklist. Two Online Communities from the UK and the USA, each with 10 COPD patients suffering from persistent coughing with excessive mucus production (self-reported by patients during screening), were run in parallel over 2 weeks. Patients completed pre-assigned tasks containing a mixture of unstructured and structured questions (Table S1), which were formulated based on our past experience of conducting such studies in multiple disease areas plus the conduct of a targeted literature review (unpublished) and social media listening study in $\mathrm{COPD}^{6}$ to ensure we captured the key topics to probe for this specific disease area, including the use of patient-friendly terms and language. Most answers were posted on the respective Online Community sites and all patients could see, react and comment. Other comments were categorized as "private" to allow patients a higher level of comfort with sharing their feelings. A trained moderator monitored and guided the Online Community discussion, answering questions, and probing deeper if required, either individually or collectively. Over the course of the study, five themes were explored with a new set of questions posted approximately every 2 days. Patients had a screen name to ensure anonymity. They were offered a fixed remuneration at fair market value for taking part in the study. Patients were able to join the Online Communities freely to follow/contribute to the developing conversations, but were requested to spend a minimum of 10 mins per day on the board and to answer all the questions posted. Tasks were structured under the themes described in Table 1. On the final day, high-level conclusions were shared with patients, to get their feedback, and patients were asked to fill in gaps or correct any misinterpretations.

\section{Patients}

A fieldwork panel recruitment agency recruited patients from the UK and the USA by using a mixed approach to recruitment: contacting charities, patient support groups, via referrals from other patients, and via digital campaigns and online marketing. Screening was completed online or 
Table I Day-wise tasks assigned to patients in the Online Communities

\begin{tabular}{|c|c|c|}
\hline Task & Theme & Task objectives \\
\hline 1 & $\begin{array}{l}\text { From first symptoms to } \\
\text { diagnosis }\end{array}$ & $\begin{array}{l}\text { - Identify initial symptoms, who gave the diagnosis and when, initial concerns and reactions to } \\
\text { diagnosis } \\
\text { - To identify spontaneous associations with COPD }\end{array}$ \\
\hline 2 & Living with COPD & $\begin{array}{l}\text { - To identify the physical and psychological elements of living with COPD } \\
\text { - To understand the biggest impacts that COPD has on patients' lives and the strategies they put } \\
\text { in place to best cope with these }\end{array}$ \\
\hline 3 & Symptoms of COPD & $\begin{array}{l}\text { - To understand the impact of cough, mucous secretion and other signs (sleeplessness, urinary } \\
\text { incontinence, etc.) on patients' quality of life and emotional well-being } \\
\text { - To identify unmet needs in coping with symptoms }\end{array}$ \\
\hline 4 & Your ideal COPD medication & $\begin{array}{l}\text { - To understand patients' treatment goals; how they would determine "success" of a treatment, } \\
\text { what measures they would refer to } \\
\text { - To identify the unmet needs in relation to current available treatment options }\end{array}$ \\
\hline 5 & $\begin{array}{l}\text { Reducing the impact of COPD } \\
\text { on the patient's life }\end{array}$ & $\begin{array}{l}\text { - To explore patient's involvement with digital health services currently available } \\
\text { - To identify unmet needs in relation to treatment support services } \\
\text { - To explore new ways of improving patients' quality of life }\end{array}$ \\
\hline
\end{tabular}

Table 2 Screening criteria for participation in the Online Communities

\section{Criteria}

Age: a mix of ages in the UK, but in the USA, patients were primarily aged $>50$ years

A diagnosis of COPD at least 6 months prior to recruitment

Had experienced persistent coughing or excessive mucus production

In the USA: a majority of patients from Medicare

Have access to a mobile phone or computer for study participation

over the phone, and patients who met the inclusion criteria in Table 2 were considered eligible and invited to participate.

\section{Informed consent and ethical considerations}

Electronic consent was obtained to participate in the Online Communities, after patients had been informed of the study purpose, sponsorship of a pharmaceutical company who could be observing their online interactions, and the commitment to all laws of data protection by all parties involved in the research. Patients were informed about the level of engagement required, the remuneration for their time and their right to withdrawal. Patients interacted only with the trained moderator during the study; the members of the sponsoring pharmaceutical company had no direct contact with patients. The Online Communities were conducted in accordance with the ESOMAR, ${ }^{16}$ EphMRA, ${ }^{17}$ and Intellus ${ }^{18}$ codes of conduct regarding anonymity and confidentiality - the aim of this study was to gather patient views only, and was not in any way promotional. In the case of research conducted in the UK, the Online Community was conducted in accordance with the ABPI ${ }^{19}{ }^{M_{R S S}{ }^{20}}$ and BHBIA ${ }^{21}$ codes of conduct. Overall, this was a small online community interaction among the patients, who remained anonymous in the study. There was no physical interaction nor intervention in the study, which was solely to gather their input and insights to the questions asked (included in the supplementary information). In such circumstances for qualitative research, ethics board approval is typically considered not required and thus was not sought.

\section{Data analyses}

Data were analyzed following the principles of grounded theory. The moderator identified emerging patterns and themes (categories) in patients' answers and codified these accordingly. Constant comparative analyses were performed throughout, and all answers were summarized in an easy-to-read results page that was then discussed with the wider team. Discussions with the rest of the research team and the sponsoring company allowed for a greater depth of analysis and the emergence of additional gaps of knowledge. The moderator would go back to the data and/or ask follow-up questions to the patients to search for answers to fill those gaps. At a final stage, all information was systematically scrutinized and re-organized in overarching themes for an easier read of the results. A summary of the analyses detailing the key findings was shared with the patients for their validation 
(Table S2). This method allowed the research team to validate their conclusions and identify points of information that required further clarification and/or research.

\section{Results}

\section{Patient characteristics}

Fifty-five patients from a patient panel expressed interest in participating in an Online Community and completed the screening. Subsequently, 13 patients from the UK and 14 from the USA met the screening criteria; all patients were followed up and a total of 22 joined the Online Communities; 2 patients withdrew halfway through and did not complete all the activities. Finally, 20 patients (UK, $n=10$; USA, $n=10$ ) were fully engaged in the communities and completed all tasks. All patients selected had experienced persistent cough and excessive phlegm and mucus as symptoms associated with their COPD. Ages ranged from 38 to 74 years, $75 \%$ were female, $60 \%$ of the patients were ex-smokers and the remaining $40 \%$ continued to smoke. Patients had been diagnosed with COPD on average 6.5 years ago. In the USA, most patients were on Medicare or Medicaid insurance. Patients took a variety of inhaled medications for COPD management and treatment of cough. Detailed patient demographics and characteristics are described in Table S3.

\section{Insights from patient responses in the online communities Living with COPD}

Patients in the Online Communities indicated that COPD diagnosis is often delayed (by 3 months to over 1year). This study identifies two possible reasons for this delay: 1) patients failing to take notice of their symptoms, and 2) health care professionals (HCPs) not always proactively assessing the symptoms. Quotes from patients referring to this problem are listed in Table 3.

The psychological burden of COPD looms large among patients. Patients in the Online Communities felt guilty and judged, as they (and others) perceived that the disease was self-perpetuated through smoking. Patients associated COPD with sad memories, lack of understanding, regret, smoking, lack of support, lack of sympathy, shame, embarrassment and incapacity. Persistent cough and mucus had a substantial impact on patients' sleep quality, energy levels and ability to perform daily tasks, as evident from the patient responses shown in Table 3. It acted as a constant reminder of illness, affecting their sleep patterns and those of their partner. Based on patients' feedback, a good/bad day was highly associated with the quality of sleep. A good day associated with terms such as sleeping well, no exacerbations, having energy, having a clear throat, no excessive coughing, no mucus, etc., whereas a bad day was linked with terms such as depressed and alone, sleeping badly, coughing, no energy, unable to socialise with family and friends, etc. This study revealed that patients experience an internal battle to accept their limitations and adapt their lifestyle to cope with their condition; acceptance of their limitations was identified by patients as a key initial step toward a more positive outlook. Smoking cessation was identified as an inflexion point that could determine the relationship of these patients with their condition; being more positive for those who manage to quit smoking.

\section{Impact of COPD symptoms}

Impact of cough and mucus on daily lives

Patients in the Online Communities used the terms mucus or phlegm plus some slang terms (Table 3) when talking about this symptom, both within this study and also in conversations with their friends and family. They did not use the word sputum, a term commonly used by physicians.

Patients' sleep quality, energy levels and ability to perform daily tasks are substantially affected by cough and mucus, which were most bothersome at night, sometimes accompanied by uncontrollable coughing attacks, which caused sleep disturbances that had a knock-on effect on patient's sleep quality. Feeling unrested in the morning affected their mood the following day (Table 3). Mucus accumulation in the back of the throat caused a sense of suffocation during the night, such that patients woke up experiencing panic attacks ("drowning in mucus"). As indicated in their responses, for some patients, the act of clearing mucus in the morning became a daily routine or ritual that could take up to $2 \mathrm{hrs}$ or more (Table 3). The effort of clearing the mucus was extreme and often exhausting. Patients in the communities also mentioned the need to take breaks during the day to expel mucus ("needing time and a place to do this"; "not always easy in the work environment"). The lack of a restful nights' sleep and the morning battle of coughing and expulsion of mucus left many of these patients feeling exhausted. Thus, a vicious cycle was taking place: the resultant fatigue meant a reduced ability to engage in even the simplest of daily tasks. Some patients mentioned struggling to maintain their jobs while others had to reduce their 


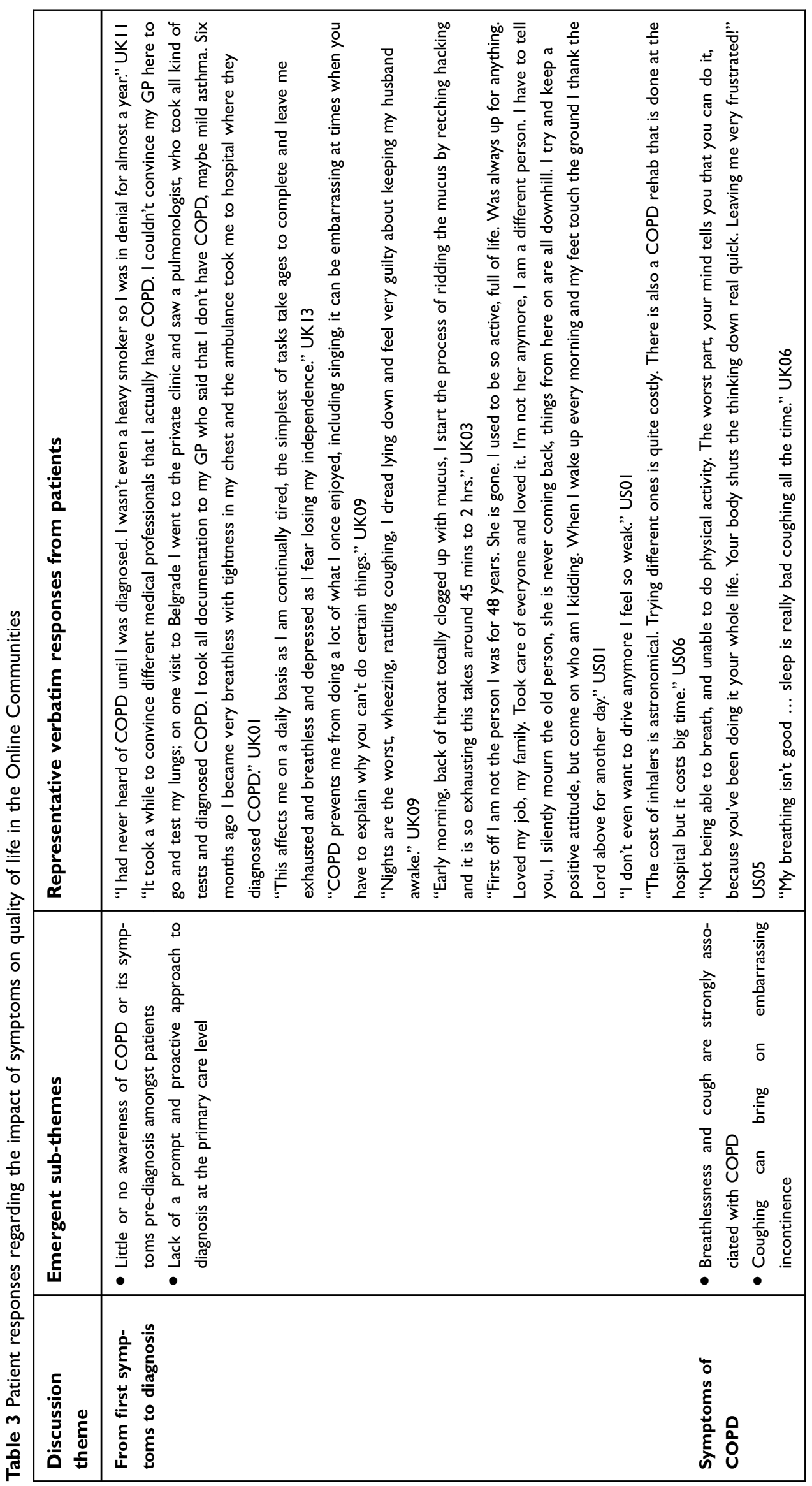


working hours (Table 3). Additionally, patients frequently showed feelings of guilt and self-blame due to the perceived self-inflicted nature of COPD, from smoking.

\section{Impact of cough and mucus on social engagements}

Most COPD patients in the Online Communities experienced feelings of low self-esteem, and were hesitant to venture out in public because of their uncontrollable coughing and mucus expectoration, and tended to stay home instead. Some patients did not wish to be "defined" by their illness. Their persistent coughing hindered their ability to hold conversations and worried other people, who often tried to help, but instead, further embarrassed the patient. In addition, the lack of understanding shown by family and friends (according to the patient) left them feeling "isolated", "depressed" and "misunderstood". Patients also feared coughing attacks during driving, with the result of limiting their driving or taking taxis/depending on others, since public transport was also "out of bounds". They would often avoid social interactions which led to further isolation and in some cases depression. Verbatim responses described in Table 3 reflect this impact. Furthermore, some patients constantly needed to explain and apologize to others, especially strangers, if these coughing/mucus fits happened in public. Even with family members, eg, with grandchildren, there were sentiments of embarrassment and shame that affected their social life and self-image (Table 3).

\section{Financial impact of symptoms}

Patients reported the impact of additional costs related to COPD management and expensive medications used to treat the symptoms (Table 3).

\section{Impact of cough and mucus on incontinence}

Two of the 20 patients in the Online Communities spontaneously brought up the subject of incontinence. However, when asked directly on an individual basis by the moderator, it transpired that incontinence was a problem for 13-20 patients. Incontinence was associated with excessive coughing in most patients. As stated in their responses (Table 4), incontinence triggered by cough led to fewer social engagements and also affected relationships and intimacy of COPD patients. Patients delayed the use of incontinence pads mainly for economic reasons and feelings of low selfesteem; many used them only if they were going out in public. Moreover, when patients mentioned incontinence to their physicians, they found them to be unsympathetic and unhelpful.

\section{Treating COPD (ideal COPD medication)}

Patients' desired treatment goals included getting rid of coughing, having restful nights, reducing the excess mucus, combating shortness of breath and being able to get back to being "their old self" (do the things they used to do before diagnosis), as shown in Table 5. Shortness of breath, coughing and mucus were the symptoms that patients wanted to reduce the most.

Patients expressed different levels of awareness of COPD treatments currently on the market. In general, they perceived that the current treatments were not helping them achieve their treatment goals. This caused frustration, as their current medication was only managing some of their symptoms but not addressing the cause of the problem (relevant verbatim responses listed in Table 5). Importantly, there were no treatments that were successful in addressing their struggles with persistent cough and excess mucus.

Table 4 Patient responses regarding urinary incontinence caused by cough

\begin{tabular}{|l|l|}
\hline $\begin{array}{l}\text { Emergent themes regarding the impact } \\
\text { of urinary incontinence }\end{array}$ & Representative verbatim responses from the patients \\
\hline - Urinary incontinence brings embarrassment to & $\begin{array}{l}\text { "At least once per month I cough and wet myself. I don't use pads but do if I have to go out." } \\
\text { UKI3 }\end{array}$ \\
$\begin{array}{l}\text { - Patients, especially in public } \\
\text { - Patients' close and intimate relationships suffer }\end{array}$ & $\begin{array}{l}\text { "My incontinence forced me to avoid intimacy." UKII } \\
\text { - Physicians are not very helpful }\end{array}$ \\
& $\begin{array}{l}\text { "Yes I did speak to doctor [he said:] "if it gets to the point where you can't cough at all } \\
\text { "It was more of a problem 2 years ago but when I did talk to my pulmonologist about he just } \\
\text { kind of blew me off by just saying ummm. I was trying to find out if this was normal, not } \\
\text { normal but goes with COPD." US09 }\end{array}$ \\
\hline
\end{tabular}




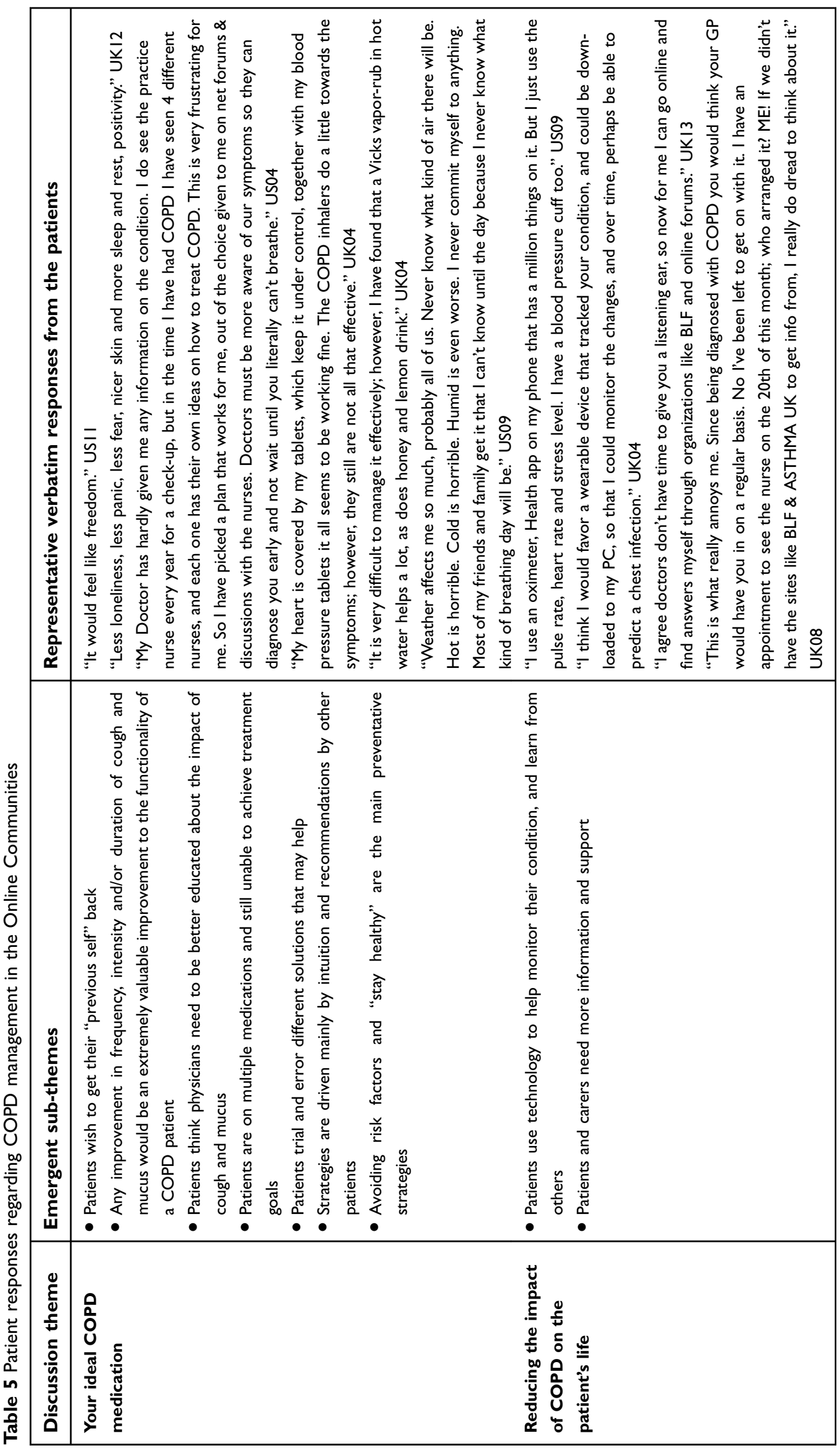


Patients in the Online Communities thought that physicians did not spend enough time to explain the purpose of each drug. Some patients were frustrated with their physician's ability to help them with their disease management approaches and sought out "herbal" remedies for their cough and mucus, mainly online (ie, use of turmeric, ginger, cannabis oil, etc.). Apart from smoking cessation, patients turned to avoiding cold weather, avoiding polluted/smoky/dusty environments, regular use of prescribed medications (inhalers, decongestants), more healthy eating/drinking, more water/cut down on coffee, etc. to prevent symptoms.

\section{Reducing the impact of COPD on the patient's life}

Patients in the Online Communities showed a desire to gain more information, especially about the latest research and treatment options in COPD; this was in light of the perception that patients received little information from their physicians (Table 5). Patients expressed frustration toward the current treatment regimens - they wanted more therapeutic options addressing the cause of the problem or alleviating the other symptoms not currently addressed by the available treatment options (ie, persistent cough and mucus). Patients feared the stigma associated with COPD, and showed a desire to increase general public education on the disease (Table 5).

Major sources of information for patients included social media platforms (eg, Facebook groups) and other more specialized websites (eg, British Lung Foundation website in the UK, WebMD in the USA). Patients reported that they could benefit from more information on understanding COPD, more emotional support, and breathing exercises; they desired to know more about current research through newsletters, awareness campaigns, etc.

\section{Discussion}

This qualitative research study using an Online Community provides first-hand account of patient experience and unmet needs in COPD, with a specific focus on cough, mucus and incontinence. In line with the recent study by Bairdini et $\mathrm{al}^{22}$, there is little awareness among the patients in our Online Communities about what causes COPD; furthermore, a belief that it is a self-inflected disease leaves patients feeling guilty, judged and isolated by others. Therefore, there is a need to better understand the emotional and psychosocial battle that they go through. HCPs in particular, but also family, friends, society in general need to recognize the impact of the debilitating symptoms of COPD on these patients.

Recent studies have shown that the symptom burden in COPD patients remains high, despite the use of dual or triple bronchodilator therapy. ${ }^{23}$ In our study, it was evident that cough and mucus had a substantial impact on the QoL of these patients at all levels, including functionality, social engagements, emotional well-being and financial impact (Figure 1).

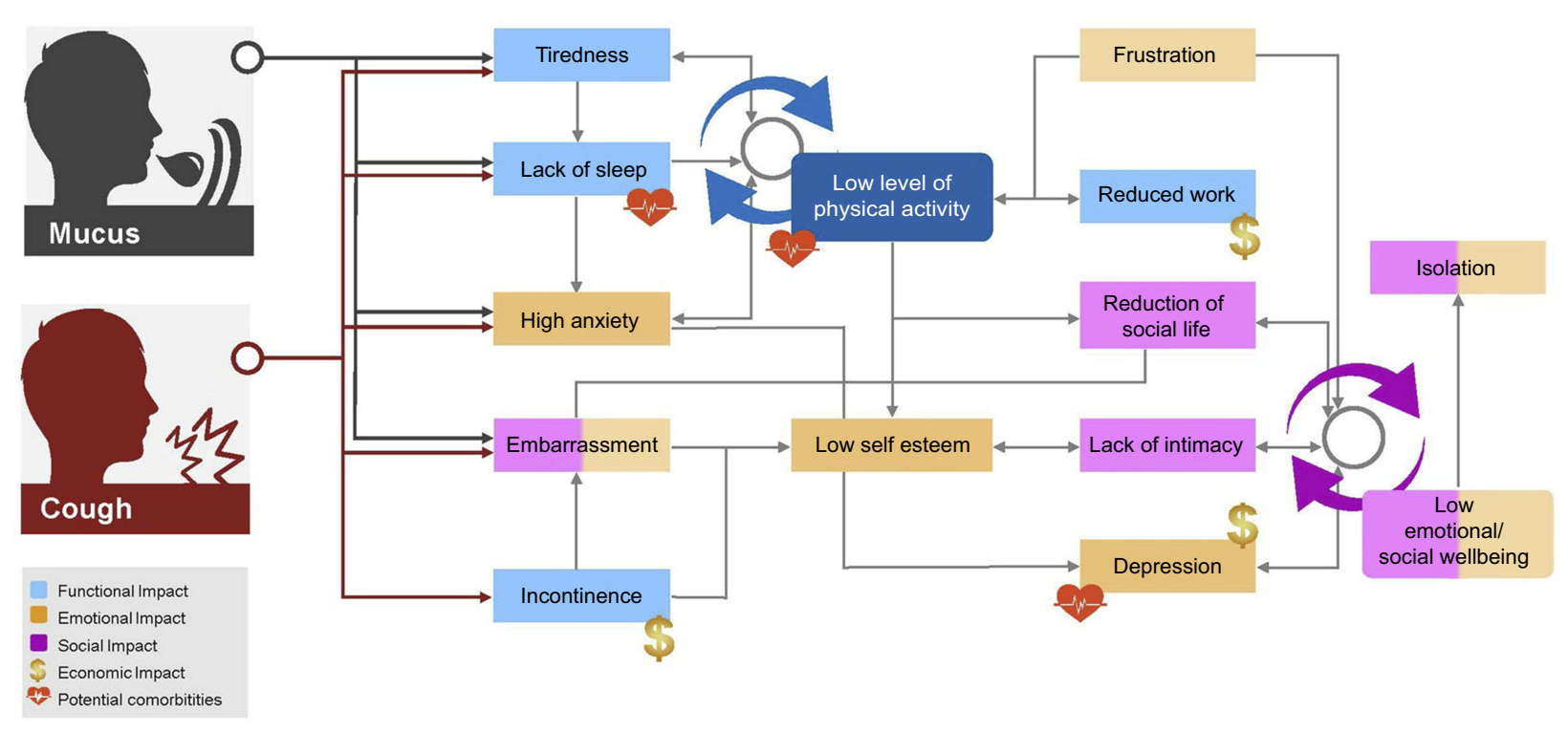

Figure I Consequences of cough and mucus in COPD patients. 
Our findings on the negative impact of symptoms on COPD patients are in line with real-world evidence indicating early-morning and night-time symptoms contribute to a significantly worse QoL. ${ }^{24,25}$ Increased coughing, shortness of breath, fatigue and increased sputum production were identified as having the greatest impact on patient wellbeing in the PERCEIVE study conducted in Germany, France, Italy, Spain, the UK and the USA. ${ }^{26}$ Notably, a multicentre, prospective study on COPD patients showed that deterioration in QoL was correlated with significant increases in coughing, and expectoration. ${ }^{27}$

Patients in our Online Communities reported that cough and mucus impacted their sleep, daily mood, energy levels and ability to perform day-to-day activities. Previously, in a European observational study investigating perceptions of symptoms and their impact on daily life activities among patients with COPD, most patients reported experiencing $\geq 1$ COPD symptom during the previous week, while $33-50 \%$ of patients reported that their COPD symptoms affected them the most during each day of the previous week. ${ }^{28}$

Urinary incontinence was revealed as being a problem in two-thirds of patients in the Online Communities, in line with previous reports that have indicated a high prevalence of urinary incontinence in patients with COPD. ${ }^{29-31}$ There was an association of symptomatic cough and mucus with urinary incontinence in these patients, ${ }^{32}$ although the evidence varies on these. In this study, urinary incontinence significantly affected the emotional well-being of COPD patients; furthermore, patients were reluctant to use incontinence pads, due to the costs of their regular use and the negative impact on their intimate life. Patients reported unsympathetic and unhelpful responses from physicians during discussions about their condition, which suggests that despite its significant impact on patients, urinary incontinence remains unaddressed in COPD treatment and there is a need for improved assessment and management of this condition.

It was demonstrated that COPD patients experience worse psychological functioning and greater emotional distress than patients with many other chronic medical conditions, ${ }^{33}$ a fact that HCPs seemingly underappreciate. For patients in our Online Communities, COPD diagnosis generated a feeling of guilt and grief. Moreover, persistent cough and mucus were perceived as a constant reminder of their "COPD self", heavily linked to negative emotions. A loss of independence, lack of emotional support and stigma caused by a lack of societal understanding of COPD increased patients' levels of anxiety, leading to isolation. Cough and mucus were identified as highly embarrassing symptoms, which added further to patient's alienation.

Some patients in the Online Communities felt that COPD had forced them to stop working, and that treatment of cough and mucus incurred additional expenditure, thus adding to the economic impact of COPD. A cross-sectional study conducted in the French Initiatives COPD cohort provided evidence that current cough in the previous 7 days was an important determinant of healthrelated QoL impairment in stable COPD patients. ${ }^{34}$ Nevertheless, previous studies had not demonstrated association of cough and mucus production with increased direct health care costs in COPD patients. ${ }^{35}$

Patients in the Online Communities created daily rituals and adjusted their lifestyle to cope with the impact of symptoms of COPD, in particular with persistent cough and excessive mucus production. The fear of worsening symptoms motivated these patients to use alternative disease management strategies learned mainly from other patients online; only a few had discussed these strategies with their doctors. This revealed a need for clearer guidance on symptom management strategies from specialized sources, for these patients. Patients opined that any improvement in alleviating the frequency, intensity and/or duration of cough and mucus would be an extremely valuable improvement in their ability to function.

Most patients in our study reported that HCPs failed to understand the emotional impact of the disease. This reveals a need for much more open discussion between these patients and their physicians beyond the clinical assessment. Indeed, poor concordance between physicians and patients in terms of impact of COPD symptoms have been acknowledged previously as a challenge in COPD management. ${ }^{36}$ However, although patient responses in this study may suggest a general negative relationship between patients and HCPs, there was no clear mention by the COPD patients that physicians did not attempt to build empathy with them.

HCPs should consider a more holistic diagnosis of COPD symptoms, specifically the impact of cough and mucus on patients' lives and how these symptoms are linked with other complaints for some patients (eg, sleep disturbances, fatigue, activity limitations, incontinence and psychosocial consequences). Physicians could benefit from tools and support materials that enable them to have more open conversations with their patients about the impact of cough and mucus on their lives, and the support and 
management strategies to provide them with a greater sense of control.

Patient responses in the Online Communities indicated that a treatment that alleviates cough and mucus could have a significant impact for a group of COPD sufferers. Alleviating cough and mucus has the potential to indirectly improve their disturbed sleep, minimize daytime fatigue and potentially reduce incontinence and reduce social barriers to allow them to lead a more normal life.

\section{Strengths and limitations}

The Online Communities as a research tool offered several advantages to the patients, such as the ability to convene anonymously and openly with a similar group of patients. Importantly, the Online Communities presented an opportunity for COPD patients to freely express the limitations that they experienced as a result of their symptoms. This can lead to a better understanding of the disease and approaches to its management. Further, the Online Communities provided real-time moderation with the possibility of follow-up questions for clarification or private follow-up on individual patient responses; thus, a quick question and answer exchange was possible, which kept the participants fully engaged in the research. The Online Communities were viewed as useful forums for knowledge exchange by the patients; they valued the opportunity to share personal experiences and learn from one another through the online conversation.

A novel aspect of this study was the sharing of highlevel findings from the Online Communities (similar to those shown in Figure 1) with the patients. When asked about the degree to which they concurred with our conclusions, patients' feedback at the end of the survey was very positive: they could identify with the findings, and many felt more empowered to talk to their physicians about their issues with managing COPD (Table S4). This approach provided patients with a chance to critique or add to our summary, and to ensure that the high-level insights and associations we had drawn from the online conversations were correct. This sharing back with the patients made them feel that the time they invested in the Online Communities was worthwhile.

As with other qualitative research tools, ${ }^{37}$ a limitation of this Online Community research is the lack of non-verbal cues that can enliven and enrich in-person research. Our study also excluded individuals without access to the internet for participation in the communities. The sample size of our study was small and we cannot necessarily extrapolate to the broader COPD patient population; on the other hand, a smaller group led to formation of close relationships among the patients that enhanced the open and frank discussion, which was of particular importance while investigating more emotional and embarrassing issues (such as incontinence). Notably, this was an exploratory insights study and quantification of the insights in terms of patient symptom burden, is being investigated in a follow-up quantitative patient preference study.

\section{Conclusion}

Our study uncovers the important needs of COPD patients not adequately addressed by currently available therapies. Findings of this study have demonstrated the significant impact of the disease on these patients, thus exemplifying the need for more improved disease management strategies. Our study explored the negative functional and emotional impact of cough and mucus on the QoL of COPD patients, further highlighting significant unmet needs in these patients. Along with the physical distress, low self-esteem and emotional well-being of these patients seem to stem from their cough and mucus. If effective management strategies for cough and mucus could be put in place, the emotional burden could be alleviated. The Online Communities were an effective methodology to understand more socially embarrassing issues such as incontinence in COPD patients, issues not revealed in research investigations with more traditional face-to-face methodologies. Ultimately, the effectiveness of using a qualitative research tool like an Online Community to explore the impact of COPD symptoms and respective unmet needs was reflected in the positive feedback from the participating patients.

\section{Acknowledgments}

The authors thank Rahul Lad, PhD of Novartis for providing medical writing and editorial support. The project was funded by Novartis Pharma AG in accordance with Good Publication Practice (GPP3) guidelines. The authors also thank Ipsos Healthcare for conducting the fieldwork on behalf of Novartis. This study was funded by Novartis Pharma AG.

\section{Author contributions}

All authors contributed to data analysis, drafting or revising the article, gave final approval of the version to be published, and agree to be accountable for all aspects of the work. 


\section{Disclosure}

$\mathrm{NC}$ is an employee of Novartis Pharma AG; NC has nonfinancial involvement in the following working groups and activities: Innovative Medicines Initiative-Patient Preferences in Benefit-Risk Assessments during the Drug Life Cycle (IMI-PREFER), Health Technology Assessment international (HTAi) Patient and Citizen's Interest Group, International Society for Pharmacoeconomics and Outcomes Research (ISPOR) Patient Preferences Task Force, and National Institute for Health and Care Excellence (NICE)-Myeloma UK Patient Preferences Project. He is also a member of the HTAi Policy Forum. NL was an employee of Novartis during the study; he is now an employee of Glanbia. JG is an employee of Novartis Pharma AG. JH is an employee of Novartis Global Service Center. CK and VPK are employees of Novartis Healthcare Private Ltd. SVM is an employee of Ipsos Healthcare UK (an independent market research agency). BO is an employee of Novartis as Head of Patient Advocacy for Respiratory. AJM reports personal fees from AstraZeneca, personal fees from Pfizer, outside the submitted work; and at the time this work was conducted he was an ERS Fellow in Industry located at Novartis Campus in Basel, Switzerland. FSG is an employee of Novartis Pharma AG owning stocks through employment. The authors report no other conflicts of interest in this work.

\section{References}

1. The Global Strategy for the Diagnosis, Management and Prevention of COPD, Global initiative for chronic obstructive lung disease (GOLD) 2018. Available from: http://goldcopd.org. Accessed December 20, 2018.

2. World Health Organization. Chronic obstructive pulmonary disease (COPD). Available from: http://www.who.int/news-room/fact-sheets/ detail/the-top-10-causes-of-death. Accessed December 20, 2018.

3. Lopez AD, Mathers CD, Ezzati M, Jamison DT, Murray CJ. Global and regional burden of disease and risk factors, 2001: systematic analysis of population health data. Lancet. 2006;367:1747-1757. doi:10.1016/S0140-6736(06)68770-9

4. Calverley PM. Cough in chronic obstructive pulmonary disease: is it important and what are the effects of treatment? Cough. 2013;9:17. doi:10.1186/1745-9974-9-17

5. Muñoz A, Small M, Wood R, Ribera A, Nuevo J. The impacts of morning, daytime, and nighttime symptoms on disease burden in realworld patients with COPD. Int J Chron Obstruct Pulmon Dis. 2018;13:1557-1568. doi:10.2147/COPD.S157874

6. Gutzwiller FS, Gruenberger JB, Kaur VP, et al. Generating patient insights in chronic obstructive pulmonary disease (COPD) with social media listening study. Eur Respir J. 2018;52:PA2005. doi:10.1183/ 13993003.01675-2018

7. Smith J, Woodcock A. Cough and its importance in COPD. Int $J$ Chron Obstruct Pulmon Dis. 2006;1(3):305-314.

8. Patient-focused drug development public workshop on guidance 1: collecting comprehensive and representative input discussion document. Available from: https://www.fda.gov/drugs/newsevents/ ucm574725.htm. Accessed December 25, 2018.
9. Todres L. The humanization of healthcare: a value framework for qualitative research. Int J Qual Stud Health Well-Being. 2009;4:6877. doi:10.1080/17482620802646204

10. Anderson C. Presenting and evaluating qualitative research. Am J Pharm Educ. 2010;74(8):141. doi:10.5688/aj7408141

11. Fan VS, Meek PM. Anxiety, depression, and cognitive impairment in patients with chronic respiratory disease. Clin Chest Med. 2014;35 (2):399-409. doi:10.1016/j.ccm.2014.02.012

12. von Leupoldt A, Kenn K. The psychology of chronic obstructive pulmonary disease. Curr Opin Psychiatry. 2013;26(5):458-463. doi:10.1097/YCO.0b013e328363c1fc

13. Douglas A Make the most of online 'Bulletin board' groups for qualitative research. Available from: http://www.bain.com/publica tions/articles/make-the-most-of-online-bulletin-board-groups-forqualitative-research.aspx. Accessed December 20, 2018

14. The Association of Qualitative Research. Online bulletin board Available from: https://www.aqr.org.uk/glossary/online-bulletinboard. Accessed December 20, 2018.

15. Green Book Directory. Online bulletin board. Available from: https:// www.greenbook.org/market-research-firms/online-bulletin-boards. Accessed December 20, 2018.

16. ICC/ESOMAR International Code on Market, Opinion and social research and data analytics. Available from: https://www.esomar. org/uploads/public/knowledge-and-standards/codes-and-guide lines/ICCESOMAR_Code_English_.pdf. Accessed December 20, 2018.

17. EphMRA code of conduct. Available from: https://www.ephmra.org/ media/1044/ephmra-2017-code-of-conduct-october-2017.pdf. Accessed December 20, 2018.

18. Intellus code of conduct. Available from: https://www.intellus.org/ Standards-Guidelines/Code-of-Conduct. Accessed December 20, 2018

19. The Association of British Pharmaceutical Industry (ABPI) code of conduct. Available from: https://www.abpi.org.uk/ethics/ethicalresponsibility/disclosure-uk/resources/. Accessed December 20, 2018.

20. Market Research Society code of conduct. Available from: https:// www.mrs.org.uk/standards/code of conduct. Accessed December 20,2018

21. BHBIA Legal and Ethical Guidelines for Healthcare Market Research. Available from: https://www.bhbia.org.uk/guidelines/lega landethicalguidelines.aspx. Accessed December 20, 2018.

22. Baiardini I, Rogliani P, Santus P, et al. Disease awareness in patients with COPD: measurement and extent. Int J Chron Obstruct Pulmon Dis. 2018;14:1-11. doi:10.2147/COPD.S179784

23. Chen S, Small M, Lindner L, Xu X. Symptomatic burden of COPD for patients receiving dual or triple therapy. Int J Chron Obstruct Pulmon Dis. 2018;13:1365-1376. doi:10.2147/COPD. S163717

24. Price D, Small M, Milligan G, Higgins V, Garcia Gil E, Estruch J. Impact of night-time symptoms in COPD: a real-world study in five European countries. Int J Chron Obstruct Pulmon Dis. 2013;8:595603. doi:10.2147/COPD.S48570

25. Stephenson JS, Cai Q, Mocarski M, Tan H, Doshi JA, Sullivan SD. Impact and factors associated with nighttime and early morning symptoms among patients with chronic obstructive pulmonary disease. Int $J$ Chron Obstruct Pulmon Dis. 2015;10:577-586. doi:10.2147/COPD.S76157

26. Miravitlles M, Anzueto A, Legnani D, Forstmeier L, Fargel M. Patient's perception of exacerbations of COPD-the PERCEIVE study. Respir Med. 2007;101:453-460. doi:10.1016/j.rmed. 2006.07.010

27. Monteagudo M, Rodríguez-Blanco T, Llagostera M, et al. Factors associated with changes in quality of life of COPD patients: a prospective study in primary care. Respir Med. 2013;107:1589-1597. doi:10.1016/j.rmed.2013.05.009 
28. Kessler R, Partridge MR, Miravitlles M, et al. Symptom variability in patients with severe COPD: a pan-European cross-sectional study. Eur Respir J. 2011;37:264-272. doi:10.1183/09031936.00051110

29. Hirayama F, Binns CW, Lee AH, Senjyu H. Urinary incontinence in Japanese women with chronic obstructive pulmonary disease: review. J Phys Ther Sci. 2005;17:119-124. doi:10.1589/jpts.17.119

30. Jarad NA, Patel P, Buswell G. Epidemiology and risk factors of urinary incontinence in patients with chronic obstructive pulmonary disease (COPD). West Engl Med J. 2015;114(3):1-3.

31. Maggi S, Minicuci N, Langlois J, Pavan M, Enzi G, Crepaldi G. Prevalence rate of urinary incontinence in community-dwelling elderly individuals: the Veneto study. J Gerontol A Biol Sci Med Sci. 2001;56(1):M14-18. doi:10.1093/gerona/56.1.M14

32. Hrisanfow E, Hägglund D. Impact of cough and urinary incontinence on quality of life in women and men with chronic obstructive pulmonary disease. J Clin Nurs. 2013;22(1-2):97-105. doi:10.1111/ jocn.2012.22.issue-1pt2
33. Dury R. COPD and emotional distress: not always noticed and therefore untreated. $\mathrm{Br} J$ Community Nurs. 2016;21:138-141. doi:10.12968/bjen.2016.21.3.138

34. Deslee G, Burgel PR, Escamilla R, et al. Impact of current cough on health-related quality of life in patients with COPD. Int J Chron Obstruct Pulmon Dis. 2016;11:2091-2097. doi:10.2147/COPD. $\mathrm{S} 106883$

35. Wacker ME, Kitzing K, Jörres RA, et al. The contribution of symptoms and comorbidities to the economic impact of COPD: an analysis of the German COSYCONET cohort. Int J COPD. 2017;12:34373448. doi:10.2147/COPD.S141852

36. Miravitlles M, Ferrer J, Baro E, Lleonart M, Galera J. Differences between physician and patient in the perception of symptoms and their severity in COPD. Respir Med. 2013;107:1977-1985. doi:10.1016/j.rmed.2013.06.019

37. Anderson C. Presenting and evaluating qualitative research. Am J Pharm Ed. 2010;74:141. doi:10.5688/aj7408141

\section{Publish your work in this journal}

The International Journal of COPD is an international, peer-reviewed journal of therapeutics and pharmacology focusing on concise rapid reporting of clinical studies and reviews in COPD. Special focus is given to the pathophysiological processes underlying the disease, intervention programs, patient focused education, and self management protocols. This journal is indexed on PubMed Central, MedLine and CAS. The manuscript management system is completely online and includes a very quick and fair peer-review system, which is all easy to use. Visit http://www.dovepress.com/testimonials.php to read real quotes from published authors. 